\title{
Recorrido por el patrimonio geológico y minero de la comarca del Aranda: desde Brea de Aragón, a Illueca, Gotor, Jarque y Aranda del Moncayo
}

Josep Maria Mata-Perelló

Andrés Pocoví Juan

Joaquim Sanz Balagué

Jaume Vilaltella

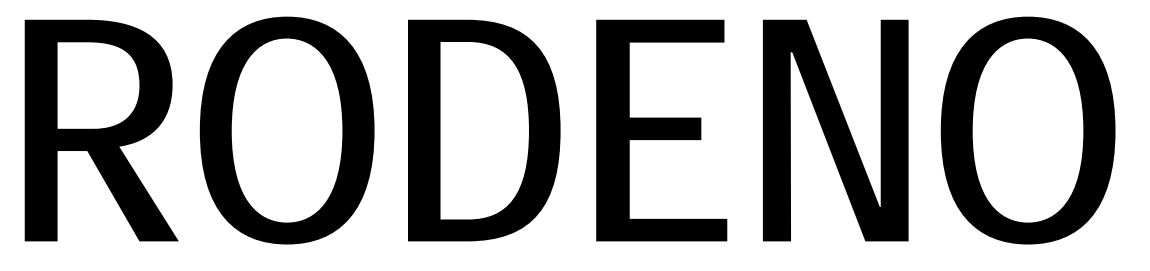

\section{REVISTA DE GEOLOGÍA ARAGONESA}

\section{n. 1}

ENERO 2015

Como citar el artículo: Mata Perelló, Josep M. [et al.] Recorrido por el patrimonio geológico y minero de la comarca del Aranda: desde Brea de Aragón, a Illueca, Gotor, Jarque y Aranda del Moncayo. En: Rodeno [revista electrónica]: revista de geología aragonesa. Manresa: Museu de Geologia Valentí Massachs, enero 2015. núm. 1. ISSNe: 1131-5393 [Data de consulta] Disponible en: http:// .. 


\title{
RECORRIDO POR EL PATRIMONIO GEOLÓGICO Y MINERO DE LA COMARCA DEL ARANDA: DESDE BREA DE ARAGÓN, A ILLUECA, GOTOR, JARQUE Y ARANDA DEL MONCAYO
}

\author{
Josep Maria Mata-Perelló \\ Museu de geologia Valentí Masachs, Escola Politècnica Superior d'Enginyeria de Manresa \\ (EPSEM), Universitat Politècnica de Catalunya · BarcelonaTech (UPC), 08272 Manresa, Spain
}

\author{
Andrés Pocovi Juan \\ Universidad de Zaragoza, Departamento de Ciencias de la Tierra ( DCT- UZ) \\ Joaquim Sanz Balagué \\ Departament d'Enginyeria Minera i Recursos Naturals (EMRN), Escola Politècnica Superior \\ d'Enginyeria de Manresa (EPSEM), Universitat Politècnica de Catalunya - BarcelonaTech \\ (UPC), 08272 Manresa, Spain
}

\section{Jaume Vilaltella Farràs.}

Sociedad Española para la Defensa del Patrimonio Geológico y Minero (SEDPGYM)

Palabras clave: patrimonio minero; patrimonio geológico; Zaragoza

\section{Resumen}

En esta ocasión se realizará un itinerario localizado en un área totalmente situada dentro la comarca aragonesa y zaragozana del Aranda, desde principio a fin, entre las localidades de Brea de Aragón y Aranda del Moncayo, pasando además por los municipios de de lllueca, Gotor y Jarque.

Por otra parte, el recorrido se centrará en su totalidad en el Sistema Ibérico. Encontrándose diferentes afloramientos de los materiales paleozoicos y también de los mesozoicos, en diferentes tramos del recorrido.

En el primer caso, nos encontraremos fundamentalmente con afloramientos de los materiales mesozoicos del Triásico, del Jurásico y del Cretácico, que encontraremos fundamentalmente entre Brea, Illueca, Gotor y Jarque. Más adelante, entorno a a Aranda del Moncayo encontraremos afloramientos de los materiales paleozoicos del Ordoviciense.

No obstante, a lo largo del recorrido nos centraremos fundamentalmente en el conocimiento del Patrimonio Geológico y Minero. Sin duda alguna, la conservación, valorización y utilización de este patrimonio es un importante factor económico a tener en cuenta. 


\section{Objetivos generales de este itinerario}

En la realización de este itinerario geológico y minero, se perseguirá la consecución de los siguientes objetivos generales, a lo largo del desarrollo del mismo:

1. Observación general de la estructura del Sistema Ibérico, a través del cual se desarrollará la totalidad del recorrido del itinerario. En concreto, el recorrido se va a realizar íntegramente por los sectores correspondientes a la Rama Aragonesa; muy cerca de su contacto con la Depresión Geológica del Ebro.

2. Observación de los materiales geológicos del paleozoico y del mesozoico que constituyen los afloramientos del Sistema Ibérico, por los alrededores de los municipios de Brea de Aragón, Illueca, Gotor, Jarque y Aranda del Moncayo. Estos materiales se distribuyen fundamentalmente entre el Paleozoico (Ordoviciense) y el Mesozoico (Triàsico, Jurásico y Cretácico).

3. Observación de las diferentes explotaciones mineras; (antiguas y actuales) tanto de las de carácter subterráneo como de las realizadas a cielo abierto. Entre estas explotaciones, y de acuerdo con el sentido de la marcha del recorrido, podemos mencionar las siguientes:

3A) Las explotaciones de las areniscas del Buntsandsteim, dedicadas a la obtención de losetas para la construcción. Se encuentran en los municipios de Gotor y Jarque, fundamentalmente.

3B) Las antiguas explotaciones de arcillas destinadas a abastecer las tejerías de Jarque y de Aranda del Moncayo. Se sitúan entre los afloramientos arcillosos del Buntsandsteim.

3C) Las mineralizaciones de cobre filonianas, que encontraremos en el municipio de Jarque, entre los materiales del Devoniano.

3D) Las mineralizaciones de cobre de carácter filoniano, situadas entre los materiales del Ordoviciense, que encontraremos en del municipio de Aranda.

3E) Las mineralizaciones estratiformes de hierro, localizadas en el municipio de Aranda, entre los materiales del Ordoviciense.

4. Observación de los impactos producidos por las explotaciones mineras sobre el Medio Natural. Y también de la corrección de estos impactos. Aunque cabe decir que no hemos encontrado ninguna restauración ambiental.

5. Observación del Patrimonio Geológico, a lo largo del recorrido. Dentro de este apartado cabe mencionar el relacionado con las mineralizaciones cupríferas asociadas a "red-beds".

6. Observación del Patrimonio Minero generado a partir de las explotaciones anteriores; así como de otras que iremos encontrando a lo largo de este itinerario. Dentro de este apartado, cabe mencionar las distintas tejeras que iremos encontrando, tanto en Jarque como en Aranda del Moncayo. 


\section{Antecedentes bibliográficos}

No conocemos la existencia de ningún itinerario similar al que ahora presentamos, que discurra por estas tierras.

Por otra parte, en relación con las mineralizaciones situadas en la comarca por la que discurre este itinerario, haremos mención de otro trabajo nuestro: MATA-PERELLÓ (1992), referidos al inventario mineralógico de esta comarca. También mencionaremos un trabajo nuestro, compartido, relativo a distintas mineralizaciones españolas: MATA-PERELLÓ y SANZ (1993).

$\mathrm{Y}$, finalmente, por lo que concierne a la estructura geológica de la zona por la que va a discurrir el itinerario, haremos mención de los trabajos de: GUIMERÀ et altri (1982) y de RIBA et altri (1976), los dos son de carácter generalista. Sin embargo, aunque son distantes al presente recorrido, nos pueden servir para tener una idea general del NE peninsular.

Todos ellos figuran en el apartado dedicado a la BIBLIOGRAFIA, al final del informe del recorrido del itinerario.

\section{Recorrido del itinerario}

El recorrido se desarrollará íntegramente por la comarca del Aranda. Así se iniciará en el municipio de Brea de Aragón, en donde no se efectuará ninguna parada. Luego, el recorrido se dirigirá hacía Illueca; ahí, en torno al municipio se efectuaran tres paradas. Tras ello, el recorrido se dirigirá hacía Gotor, en donde se efectuará una nueva parada. A continuación, el recorrido se dirigirá hacía Jarque, en donde se efectuará una hijuela con tres paradas. Luego, el recorrido se dirigirá hacía el municipio de Aranda del Moncayo, efectuándose un sinuoso recorrido que nos conducirá primero hacía el pueblo, y luego hacía la carretera de Jarque. En este recorrido efectuaremos tres paradas más, las últimas de este itinerario.

\section{Advertencias previas}

Como en otros recorridos de RECERCA GEOLÒGICA I MINERALÒGICA..., si se dispone del tiempo suficiente, podrán efectuarse todas las paradas e hijuelas indicadas en el guión. En caso contrario, recomendamos prescindir de las denominadas PARADAS - CONDICIONALES.

También es necesario, en todo momento, tener en cuenta que una parte del recorrido se efectuará por caminos de tierra, circunstancia por la cual convendrá tomar las debidas precauciones. Así se hará el recorrido, entre Jarque y las Minas de Cobre; o el que conduce desde la carretera a las Minas de Cobre de Aranda, entre otros recorridos que nos iremos encontrando.

Por último y como siempre, hay que tener a lo largo de todo el recorrido, un cuidado muy especial con la Naturaleza. 


\section{Descripción del itinerario}

Como ya es habitual, el recorrido del itinerario se estructurará sobre la base de una serie de PARADAS o ESTACIONES. En cada una de ellas se procederá a la observación de diferentes cuestiones específicas, ya sean mineras, geológicas o de tratamiento industrial de los materiales geológicos extraídos. En cada caso se indicará el número de la parada en el orden general del recorrido, el nombre de la misma (que podrá coincidir con el de la mina o el topónimo más cercano). Tras ello se indicará el nombre del municipio en donde se halla la parada, y el de la comarca. Seguidamente se indicará el número del mapa topográfico (a escala 1:50.000) en donde se halla la parada. En este itinerario, utilizaremos exclusivamente una sola hoja del Instituto Geográfico y Catastral de España: la nº 381 (llamada de Illueca). Así pues, a lo largo del presente itinerario que ahora se inicia, veremos las siguientes paradas:

PARADA 1. HORNO DE ALFARERÍA DE ILLUECA, (término municipal de Illueca, comarca del Aranda). (Hoja 381).

El recorrido cabe iniciarlo en la localidad de Brea de Aragón; aunque después cabe hacer un pequeño desplazamiento hacía la vecina población de Illueca. Una vez ahí, será necesario subir hasta las inmediaciones del Castillo, para ir después hasta el lugar en donde estaba el viejo horno de alfarería. En ese lugar haremos la primera parada tras el inicio del recorrido en Brea, habiendo recorrido unos $5 \mathrm{Km}$.

En este recorrido hemos ido encontrando afloramientos de los materiales mesozoicos, fundamentalmente del Triásico y del Jurasico. Precisamente en donde estamos ahora se observan unos depósitos arcillosos de piedemonte, procedentes de la erosión de los materiales anteriores.

En este lugar había antaño diversos hornos de alfarería en los que se aprovechaban estos materiales arcillosos. Sin embargo, poco a poco se han ido perdiendo, quedando solo los restos del que ahora estamos viendo. (fotografia 1).

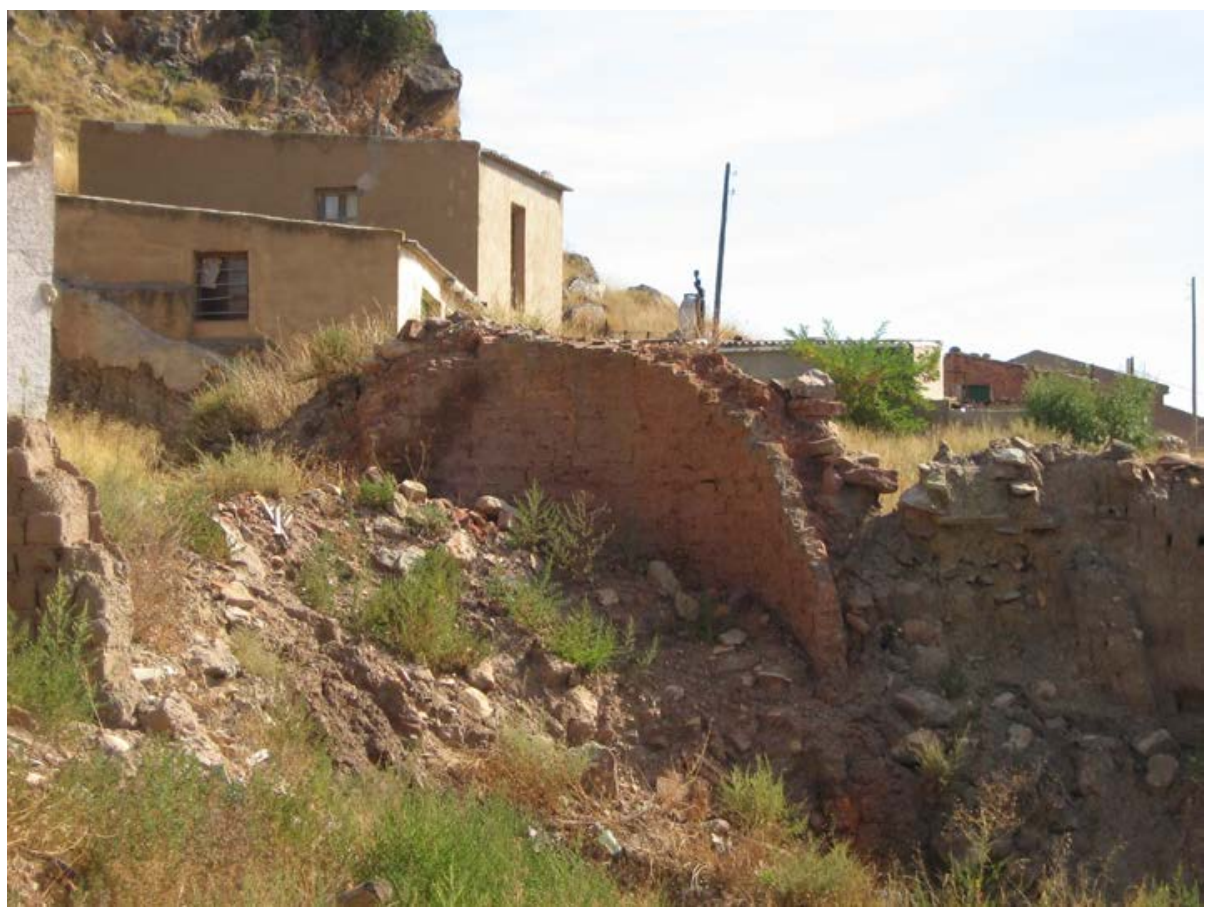

Fotografía 1. Restos del horno de alfarería de Illueca 
Finalmente, cabe indicar que este elemento forma parte del Patrimonio Minero de la comarca de Aranda y requiere protección. Y suficiente reconocimiento, incluso a pesar del estado en el que actualmente se encuentra, ya que es el único vestigio de una actividad ahora desaparecida.

PARADA 2. CALERA DE LA CARRETERA A ILLUECA, (término municipal de Illueca, comarca del Aranda). (Hoja 381).

Tras realizar la parada anterior, cabe bajar hacía el río, para tomar momentáneamente la carretera local que se dirige hacía Tierga, pero casi sin salir de Illueca. A menos de 0 ' $5 \mathrm{Km}$ del inicio de esta carretera, efectuaremos una nueva parada en las inmediaciones de una pequeña extracción de calizas. Así, desde la parada anterior, habremos recorrido apenas $1 \mathrm{~km}$.

En este recorrido habremos ido encontrando afloramientos de los materiales mesozoicos citados en la parada anterior, especialmente de los niveles carbonatados del Jurásico, que son los que afloran en el lugar en donde estamos situados, y en donde estos has sido otrora explotados.

A poca distancia de la explotación, remontando el barranco, se encuentra una vieja calera. En ella se utilizaban los materiales extraídos en la explotación, junto con otros procedentes de pequeñas explotaciones similares situadas barranco arriba de donde ahora estamos situados.

La calera se halla en un irregular estado de conservación, haciéndose muy patente la parte alta del horno. Este elemento también forma parte del patrimonio minero de la comarca del Aranda. (fotografia 2).

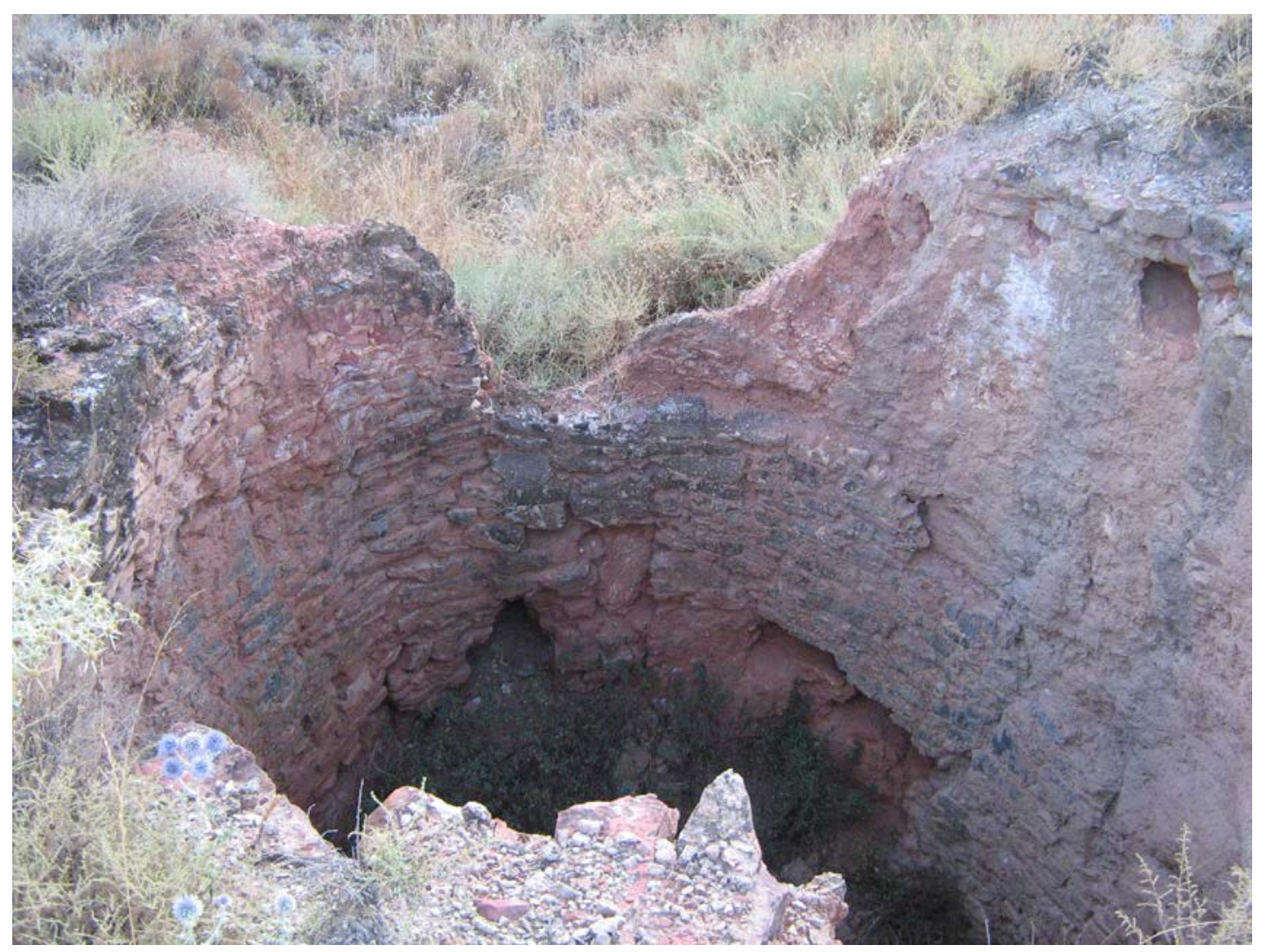

Fotografía 2. Parte alta de la calera 
PARADA 3. PLIEGUE DEL CERRO DEL CASTILLO, (término municipal de Illueca, comarca del Aranda). (Hojas 381).

Tras realizar la parada anterior, cabe retornar hasta el puente sobre el río Aranda. Luego, puede ser interesante ir al Polígono Industrial del río, tomando un camino que baja, junto al mismo, recorriéndolo unos 100 metros a pie. Así, desde la parada anterior habremos efectuado un nuevo recorrido de casi $1 \mathrm{Km}$.

En este recorrido, habremos encontrado los materiales citados en las paradas anteriores, aunque ahora se hallan recubiertos por terrenos cuaternarios, fundamentalmente de derrubios de pendiente y de aporte fluvial.

Desde este lugar, mirando hacía Illueca, puede verse el flanco septentrional de un interesante anticlinal. Éste se halla entre materiales mesozoicos del Jurásico, los que antes hemos ido encontrando. (fotografia 3).

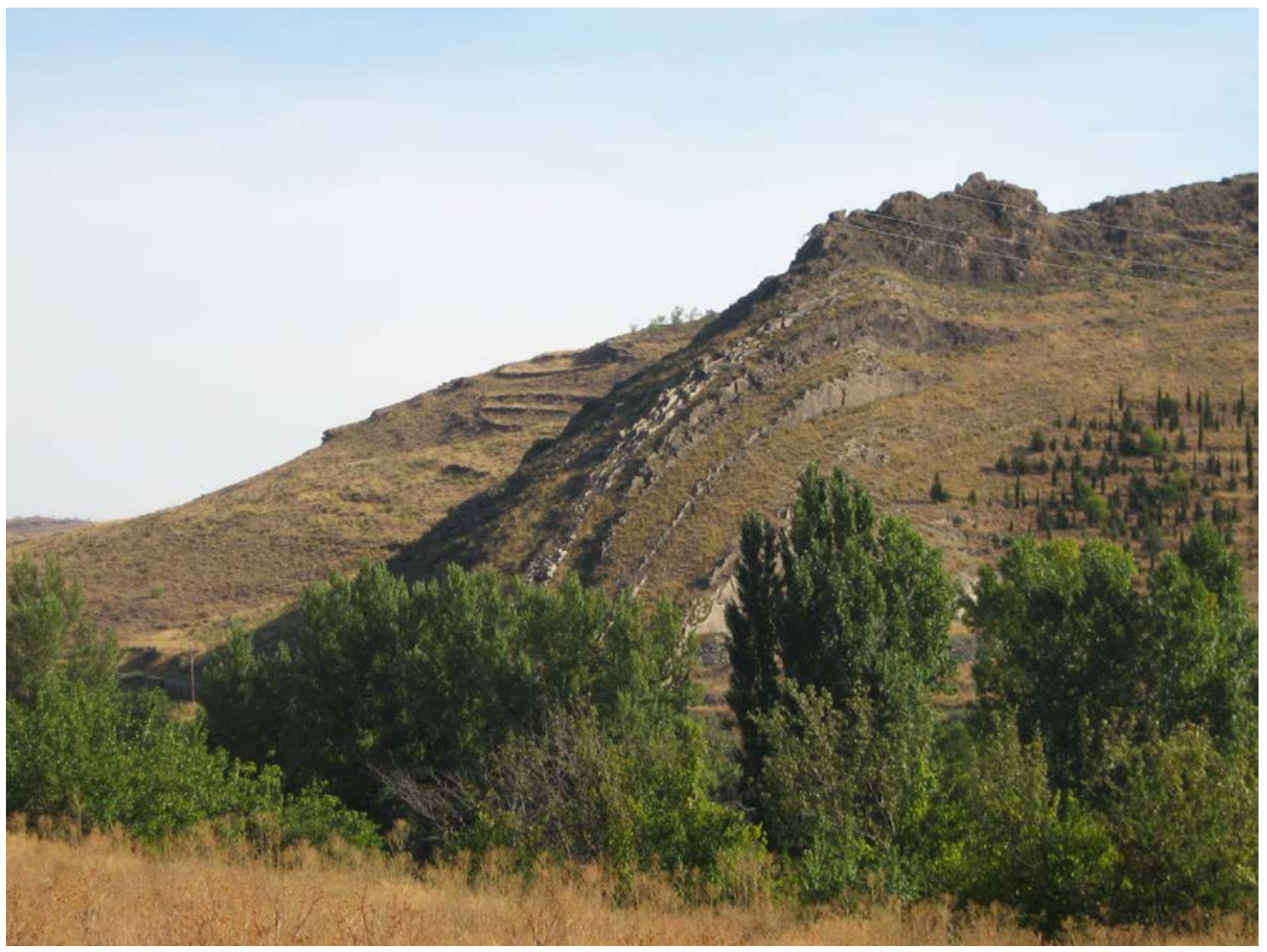

Fotografía 3. Flanco septentrional del Anticlinal del Castillo

Este pliegue, es un elemento importante del Patrimonio Geológico de la comarca del Aranda.

Por otra parte, cabe mencionar que muy cerca de donde ahora estamos halla una antigua tejera (PARADA 3 - BIS). Esta tejera se halla en un deplorable estado de conservación. Por otra parte, junto a ella había una pequeña explotación de las arcillas del Keuper que la abastecían. 
PARADA 4. EXPLOTACIONES DEL CORRAL DE LOS FRAILES, (término municipal de Gotor, comarca del Aranda). (Hojas 381).

Tras realizar la parada anterior, cabe llegar a la carretera autonómica que conduce a los inmediatos pueblos de Gotor y de Jarque. Al llegar al primero, cabe entrar en él para tomar el camino que conduce a las actuales explotaciones del Corral de los Frailes, al NNE del pueblo, a unos 3-4 Km del mismo. Al llegar ahí, efectuaremos una nueva parada de este itinerario, a unos $6 \mathrm{Km}$ de la anterior.

En este recorrido, hemos ido encontrando abundantes afloramientos mesozoicos, del Jurásico y del Triásico. Ahora, tras salir del pueblo veremos cómo van predominando los afloramientos triásicos, fundamentalmente del Triásico Inferior, del Buntsandsteim.

Cabe indicar que estos últimos son los materiales que se hallan en el lugar en donde estamos. Así, ahora vemos por doquier afloramientos de las areniscas rojas y también de las grises de este nivel.

Precisamente, en esta zona son explotados estos materiales, con la finalidad de ser utilizados como losas y losetas para la construcción. A la sazón se observan diferentes explotaciones situadas por toda la zona, tanto de las areniscas rojas como de las grises. (fotografia 4).

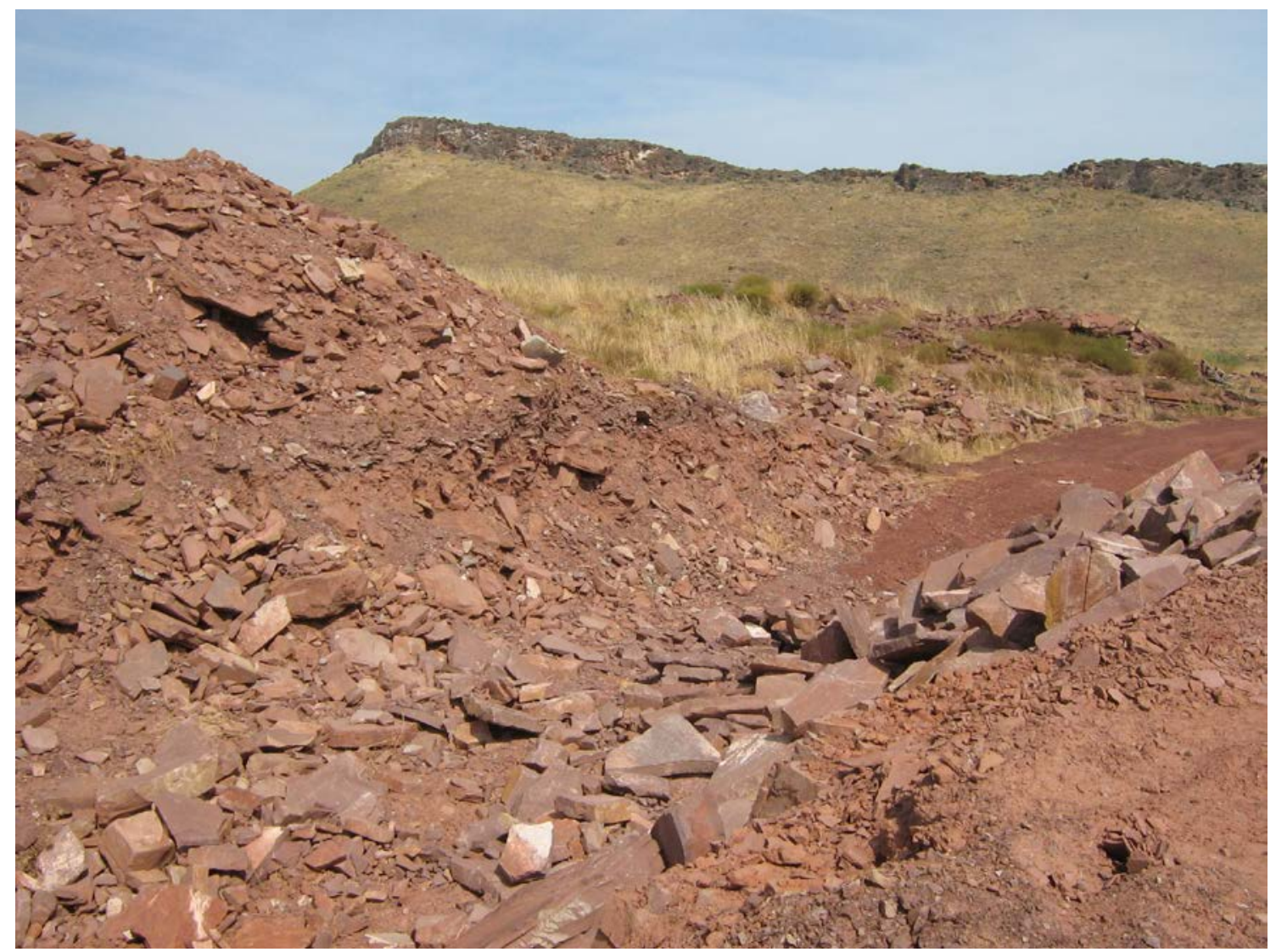

Fotografía 4. Una de las explotaciones de las areniscas rojas del Buntsandsteim en Gotor 
Cabe decir, que no hemos observado ninguna restauración entre las distintas explotaciones abiertas en toda la zona en donde nos encontramos.

PARADA 5. TEJERAS DE JARQUE, (término municipal de Jarque, comarca del Aranda). (Hoja 381)

Después de efectuar la parada anterior, es necesario retornar al pueblo de Gotor, para volver de nuevo a la carretera autonómica aragonesa, que ahora nos a de conducir hacía el vecino pueblo de Jarque. Al llegar a él, hay que cruzar el río, entrando en el pueblo, para tomar el camino - carretero que conduce al Cementerio. Tras superarlo, será necesario continuar por él, hasta llegar al camino que conduce a las tejeras (a unos 0’2 $\mathrm{Km}$ del Cementerio). Ahí efectuaremos una nueva parada, a unos $7 \mathrm{Km}$ de la anterior.

En este recorrido hemos ido encontrando los materiales citados en las paradas anteriores; aunque a menudo predominan los niveles arcillosos y yesosos del Triásico Superior, del Keuper. Precisamente, estos son los materiales que afloran aquí, en el lugar de la presente parada.

En este lugar hay un interesante e importante complejo de tejeras. Asimismo, junto a ellas se hallan las explotaciones arcillosas que las abastecían. Este conjunto se halla constituido por cinco tejeras. (fotografías 5,6 y 7 ).

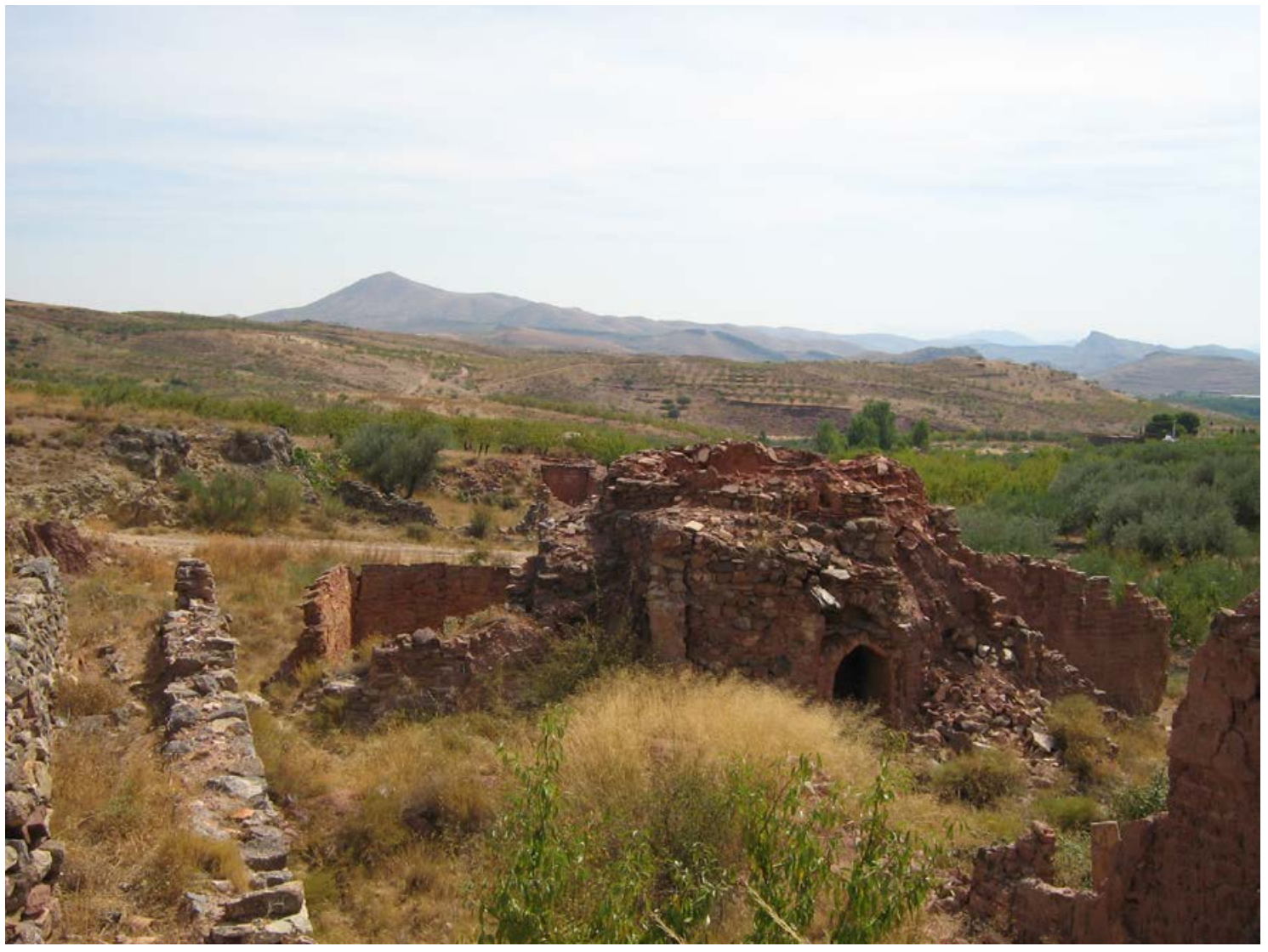

Fotografía 6. Dos de las tejeras: una a este lado del camino y otra más allá.

La fotografía está tomada desde otra de las tejeras 
Al respecto de estas tejeras, de este importante conjunto, algunas de ellas medianamente conservadas y otras recientemente restauradas, cabe decir que forman parte del Patrimonio Minero de la comarca del Aranda, y como tales deberían ser tenidas en cuenta para su valoración y protección.

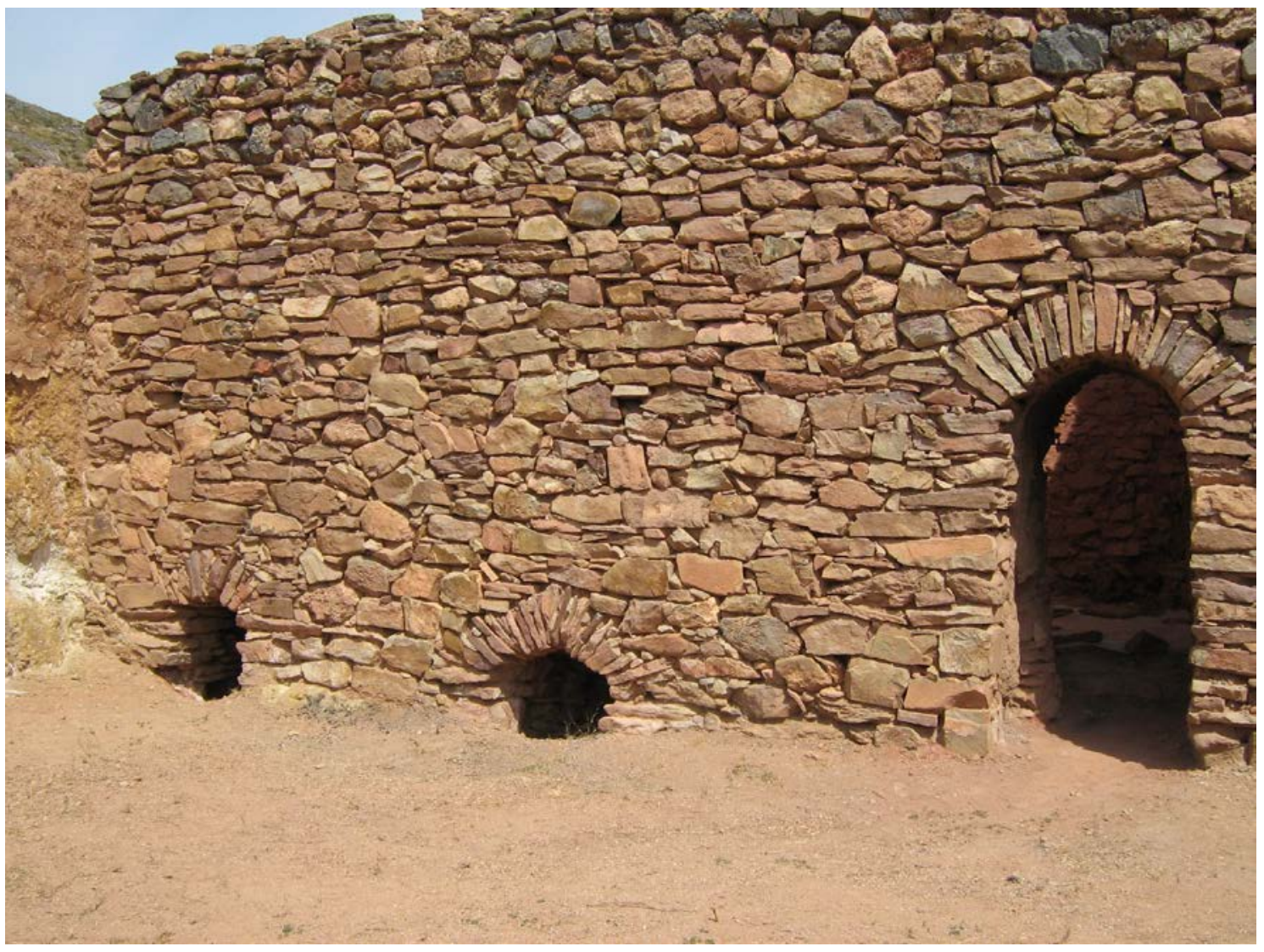

Fotografía 6. Conjunto de las tres tejeras restauradas. En la fotografía anterior quedaban al otro lado del camino 


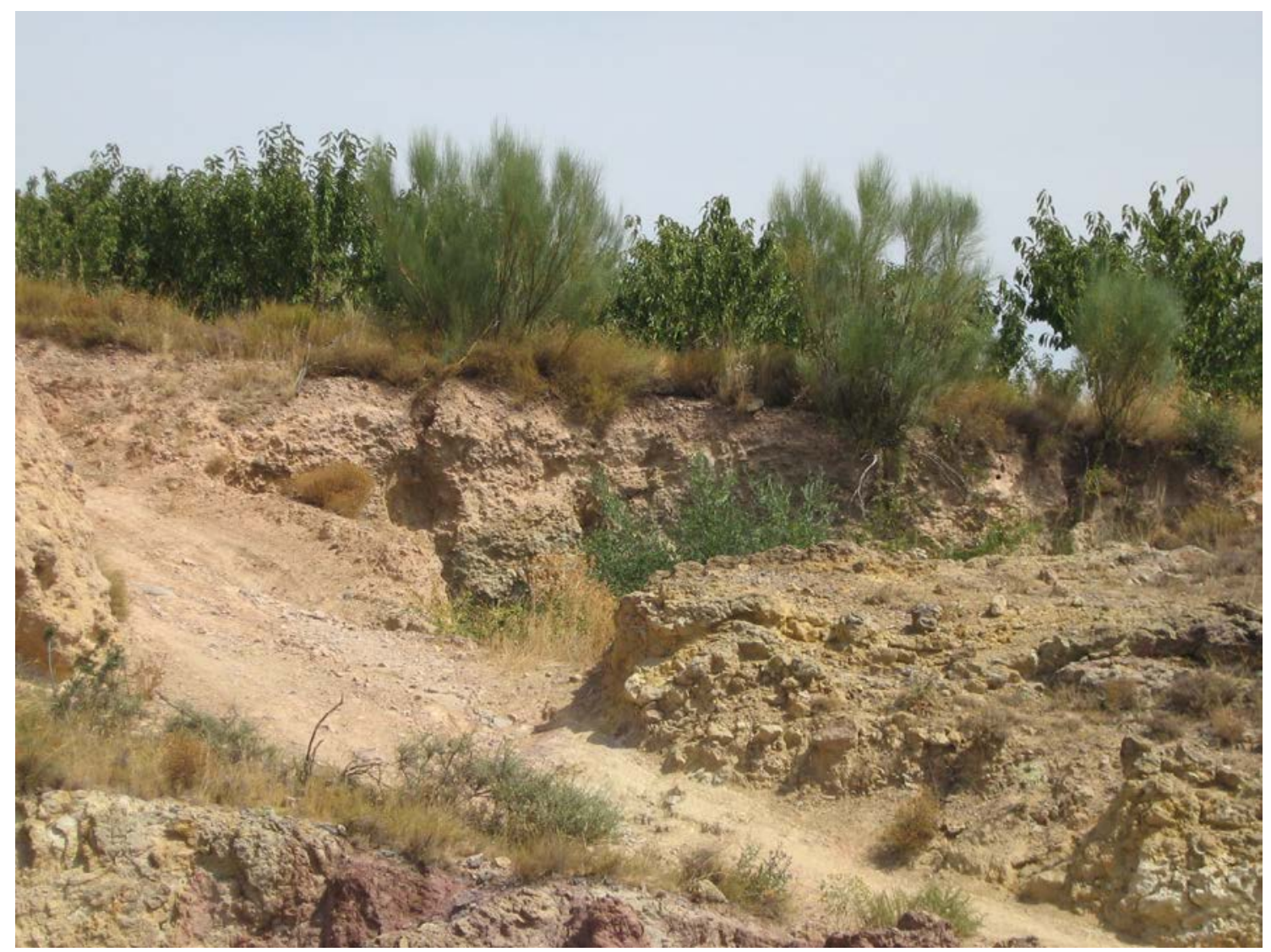

Fotografía 7. Una de las explotaciones aledañas a las tejeras

PARADA 6. MINAS DE COBRE DEL CORRAL DE VALDEOSEJA, (término municipal de Jarque, comarca del Aranda). (Hoja 381).

Después de realizar la parada anterior, es necesario continuar hacía el Norte por el camino que nos ha traído hasta el Cementerio y hasta las inmediaciones de las tejeras. Por este camino nos convendrá luego ascender hasta las cercanías del Corral de Valdeoseja. Tras pasar un pequeño collado, empezaremos a encontrar los restos de estas antiguas explotaciones mineras. Ahí efectuaremos una nueva parada dentro del recorrido de este itinerario, a unos 3 $\mathrm{Km}$ de la anterior.

En este recorrido hemos ido encontrando, fundamentalmente, los afloramientos mesozoicos de los materiales del triásico. Muy a menudo, especialmente al principio del recorrido, estos pertenecen al Keuper. Más adelante, los que predominan son los del Buntsandsteim. No obstante, en las inmediaciones del lugar de la parada encontraremos unos niveles carbonatados del Devoniano. Estos son los materiales que hay en el lugar de la presente parada.

Aquí se hace patente una mineralización cuprífera filoniana. Ésta se halla encajada entre los materiales carbonatados acabados de mencionar. Entre los minerales presentes puede citarse a los siguientes: CALCOPIRITA, PIRITA, GOETHITA, AZURITA, MALAQUITA, CUARZO. 
Por lo que concierne a las explotaciones mineras, cabe decir que se hallan prácticamente hundidas, siendo imposible ver las labores mineras. Sin embargo, la mineralización se hace bien patente junto al camino. (fotografia 8).

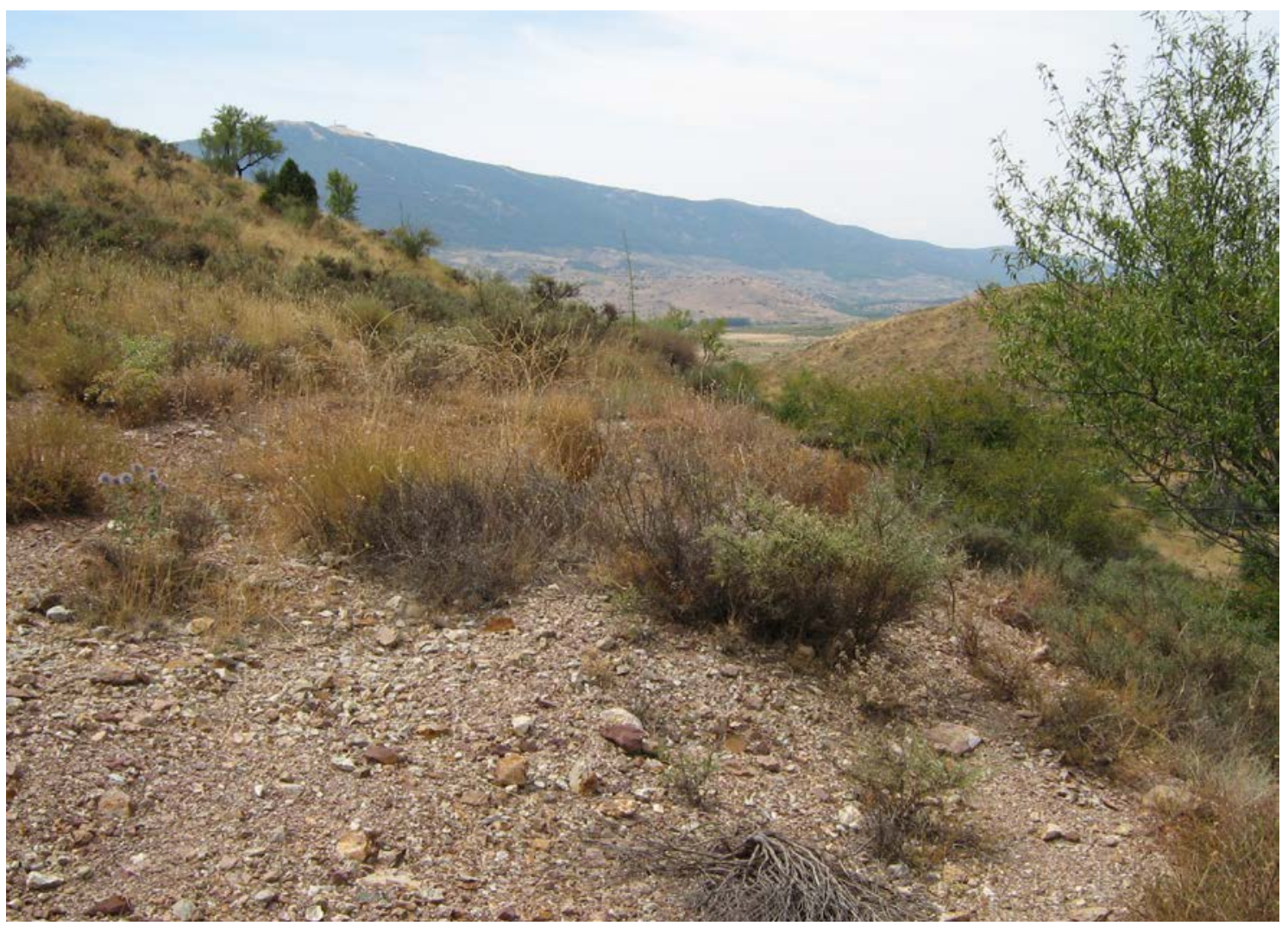

Fotografía 8. Restos de las escombreres

PARADA 7. EXPLOTACIONES DEL MOLAR, (término municipal de Jarque, comarca del Aranda). (Hoja 381).

Después de realizar la parada anterior, cabe tomar el camino que conduce hacia el monte del Molar, situado al levante de donde ahora estamos, a menos de 1'5 Km, aproximadamente.

En este recorrido hemos vuelto a encontrar los afloramientos de los materiales triásicos del Buntsandsteim. Al respecto, cabe indicar que estos últimos son los materiales que se hallan en el lugar en donde estamos. Así, ahora vemos por doquier afloramientos de las areniscas rojas y también de las grises de este tramo basal del Triásico. En efecto, estos materiales de naturaleza eminentemente detrítica jalonan todos los cerros entorno a donde ahora nos encontramos ahora situados, como el propio cerro del Molar

Precisamente, en esta zona son explotados estos materiales triásicos acabados de mencionar, con la finalidad de ser utilizados como losas y losetas para la construcción. A la sazón se observan diferentes explotaciones situadas por toda la zona, tanto de las areniscas rojas como de las grises. Es más, estas explotaciones se observan por todos los cerros circundantes en donde afloran estos materiales. (fotografia 9). 


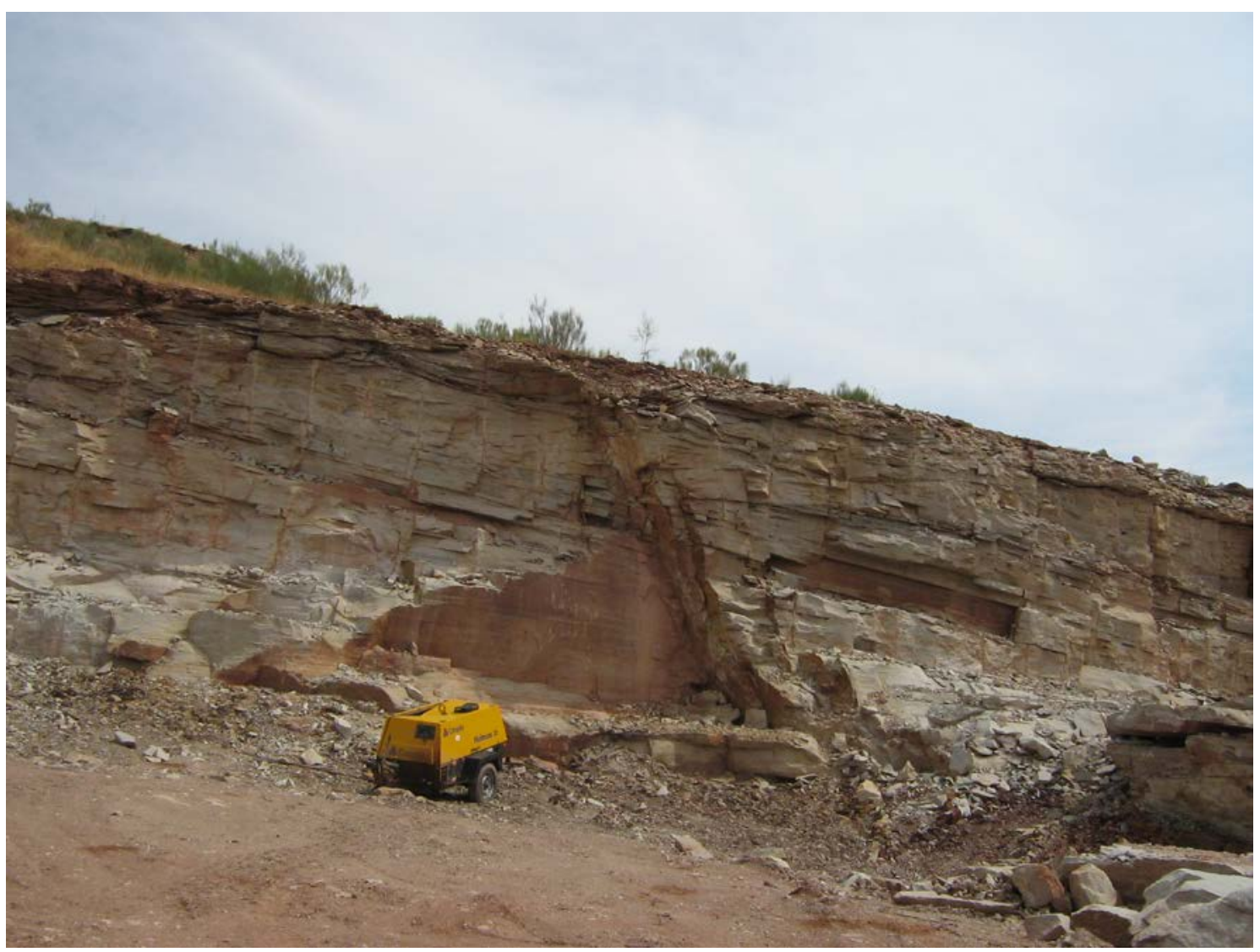

Fotografía 9. Una de las explotaciones de los niveles de las areniscas grises del Buntsandsteim

Finalmente, cabe decir que no hemos observado ninguna restauración medioambiental en ninguna de las explotaciones mineras de la zona.

PARADA 8. MINAS DE COBRE DEL COLLADO DE LAS NAVAS, (término municipal de Aranda del Moncayo, comarca del Aranda). (Hoja 381).

Tras realizar la parada anterior, es necesario retornar a Jarque, para continuar por la carretera autonómica que conduce hacía Aranda del Moncayo. Tras sobrepasar el cruce de Oseja, nos convendrá seguir por la carretera. A unos $2 \mathrm{Km}$ del cruce mencionado, nos convendrá tomar (por la derecha de la carretera) el camino que remonta el Barranco de Canales, para seguir luego el que va al Collado de las Navas. En este último camino, pronto encontraremos las minas. Ahí haremos una nueva parada, a unos $8 \mathrm{Km}$ de la anteriormente efectuada.

En este recorrido, en un principio hemos ido encontrando afloramientos de los materiales mesozoicos situados en las paradas anteriores. Sin embargo, en las inmediaciones del cruce hemos empezado a encontrar afloramientos de los materiales paleozoicos del Ordovícico. Estos son los materiales que hay en el lugar de la parada.

En este lugar había una explotación minera que beneficiaba un filón de minerales de cobre encajado entre los materiales paleozoicos. Entre los minerales presentes cabe citar a los siguientes: CALCOPIRITA, PIRITA, GOETHITA, AZURITA. MALAQUITA. EI primero como mineral primario y los dos últimos como alteraciones de este. 
Por lo que concierne a las explotaciones mineras, cabe decir que el patrimonio minero que mantienen es muy poco. (fotografia 10).

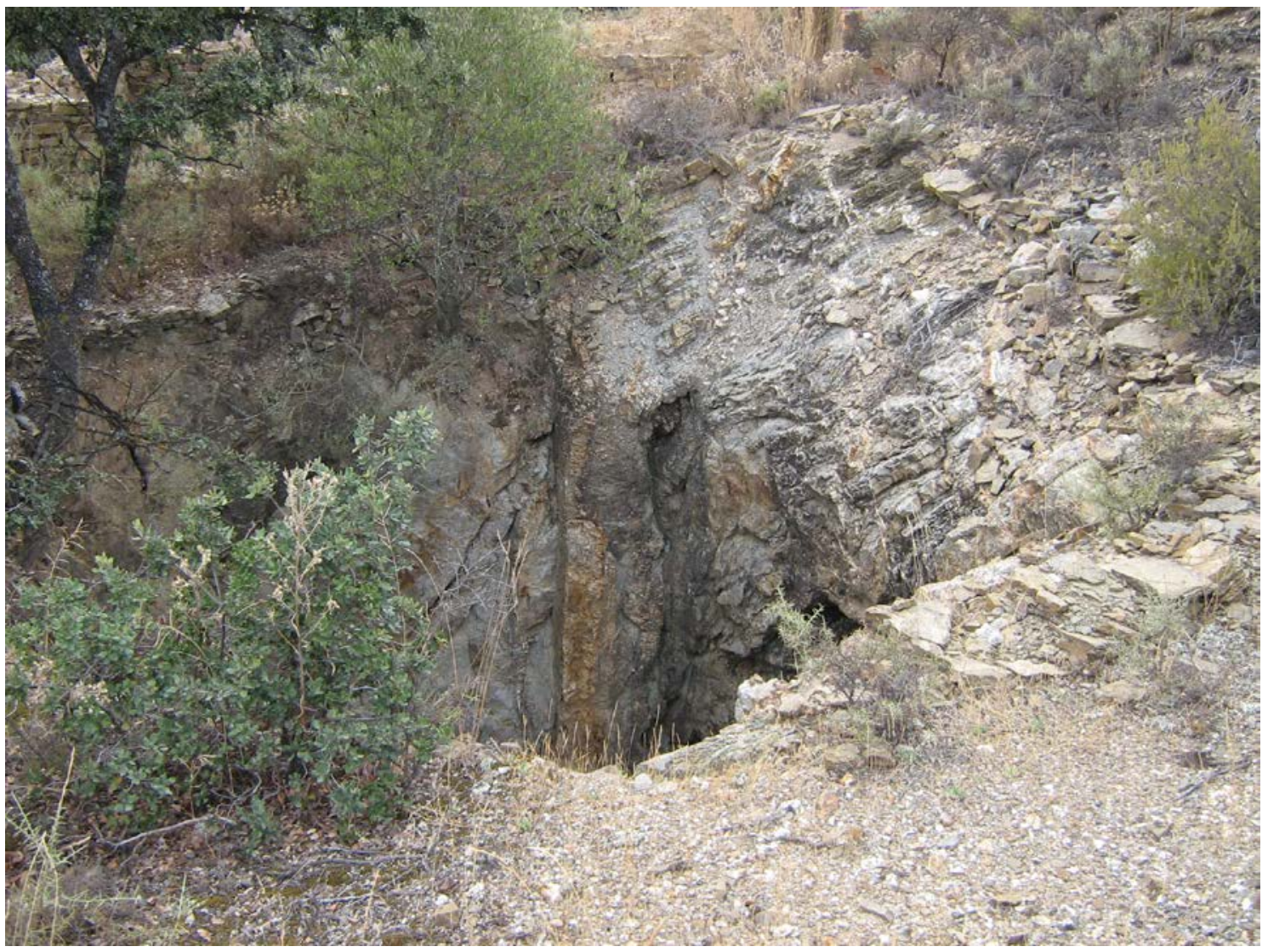

Fotografía 10. Pozo minero de las explotaciones cupríferas del Collado de las Navas

PARADA 9 - CONDICIONAL. EXPLOTACIONES DEL EMBALSE, (término municipal de Aranda del Moncayo, comarca del Aranda). (Hoja 381).

Después de la parada anterior, cabe continuar por el camino que nos ha traído hasta aquí. Este camino, nos va acercando hasta el pueblo de Aranda del Moncayo. Antes llegaremos al Embalse de la Maidevera.

Tras cruzar al otro lado por la presa, nos convendrá ir hacía unas antiguas explotaciones situadas junto al mismo embalse. En este lugar, a unos $4 \mathrm{Km}$ de la anterior, haremos otra parada.

En este recorrido habremos ido encontrando afloramientos de los materiales paleozoico, primero del Ordovícico y después del Devoniano, como los que ahora encontramos en el lugar de la parada, en donde han sido explotados para la construcción de la presa. (fotografia 11). 


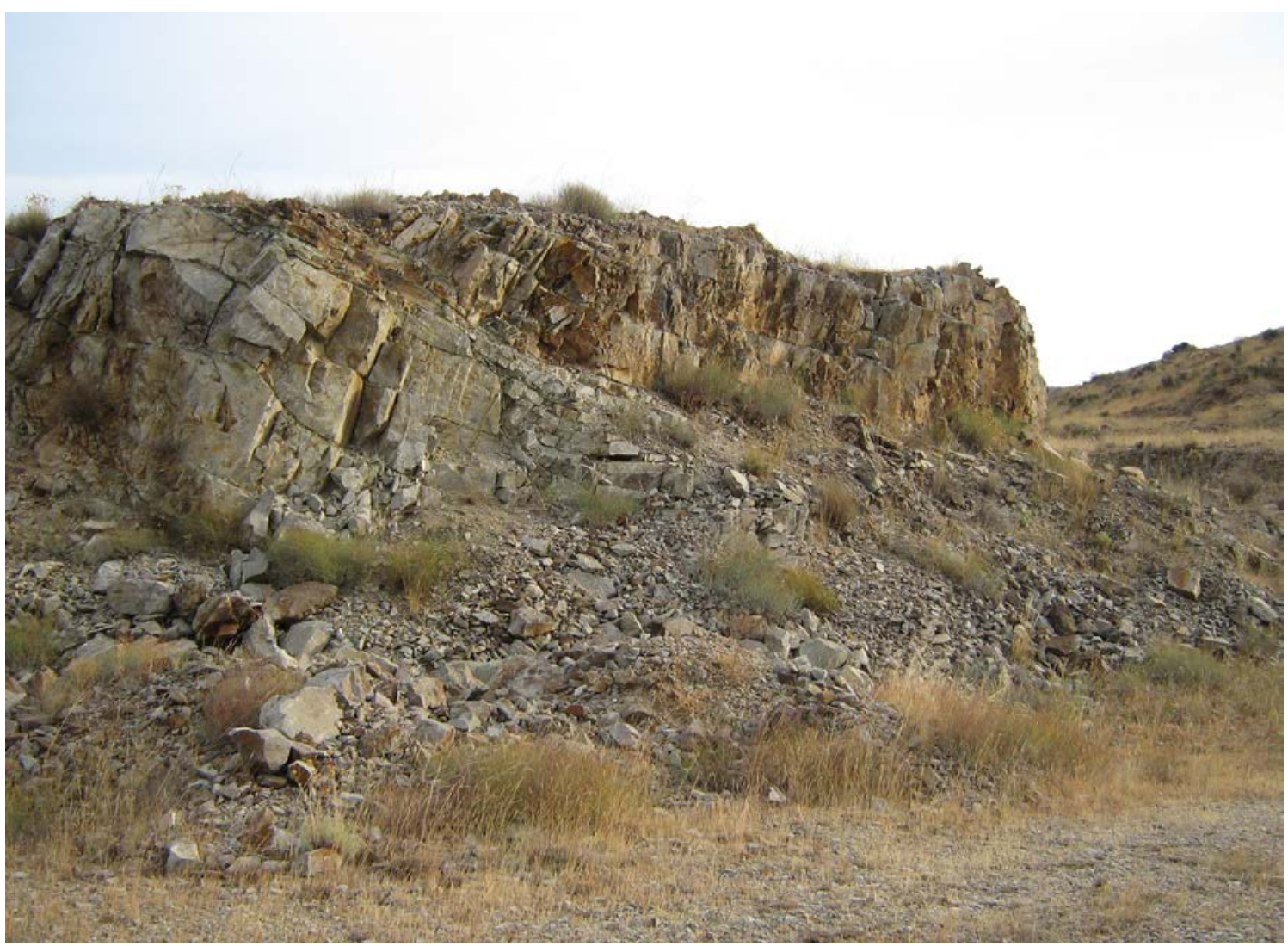

Fotografía 11. Detalle de la explotación de calizas

Por otra parte, cabe indicar que estas no son las únicas canteras calizas utilizadas en su tiempo para la construcción de la presa. Por otra parte, cabe señalar que también se utilizaron para la construcción del dique. La misión de este es la de evitar que las tierras de labor del municipio de Aranda queden preservados del agua.

PARADA 10. TEJERA DE LA CARRETERA DE ARANDA, (término municipal de Aranda del Moncayo, comarca del Aranda). (Hoja 381).

En cualquier caso, después de realizar la parada anterior, es necesario llegar a a la carretera autonómica que conduce a Aranda del Moncayo. Pronto antes de llegar efectuaremos una nueva parada en un antiguo tejar situado a la izquierda de la carretera, a unos $3 \mathrm{Km}$ de la parada anterior.

En este recorrido, al llegar a las inmediaciones del lugar de la parada volveremos a encontrar los afloramientos triásicos del Keuper. Estos son los que aparecen en el lugar de la presente parada.

Aquí se muy patente una antigua tejera muy bien conservada. En esta tejera se utilizaban los materiales extraídos en las cercanías en donde estamos (en donde aún pueden verse las antiguas explotaciones).

Por lo que concierne al tejar, cabe decir que conserva muy bien la estructura, aunque no se halla muy bien conservado. Así se observa el remate de una cúpula circular, situada por encima de la base cuadrada del horno del tejar. (fotografia 12). 


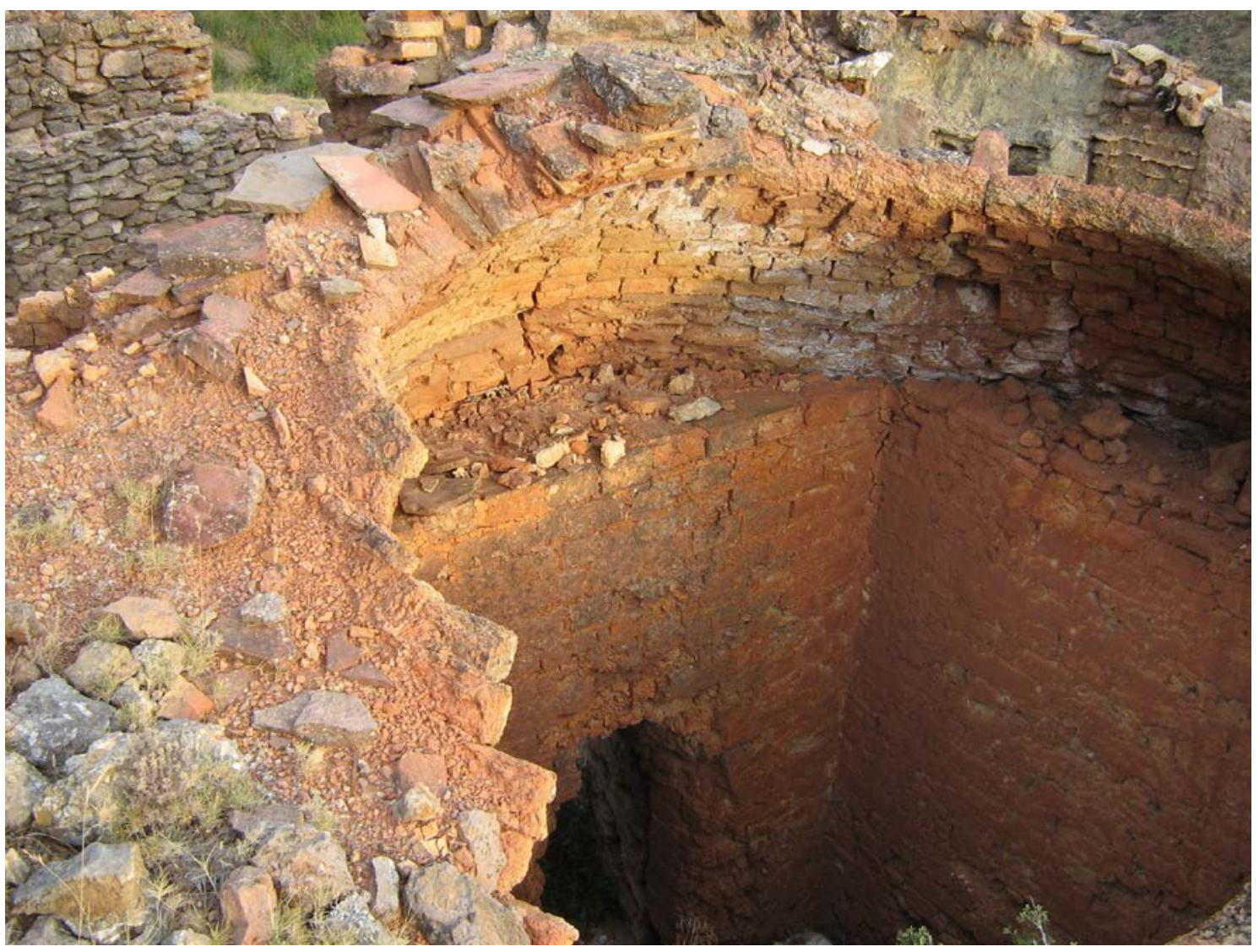

Fotografía 12. Horno cuadrado de la tejera, con una cobertura circular

Cabe señalar que esta tejera forma parte del Patrimonio Minero de la comarca del Aranda, siendo aconsejable su protección.

PARADA 11. ANTIGUAS MINAS DE HIERRO DEL BARRANCO DE VALDAVIA, (término municipal de Aranda del Moncayo, comarca del Aranda). (Hoja 381).

Tras realizar la parada anterior, cabe volver atrás por la carretera, yendo ahora hacía Jarque, Brea e Illueca. Poco antes de llegar al puente sobre el Barranco Canales (por donde hemos pasado anteriormente, por el camino que iba a las Minas de las Navas), efectuaremos una nueva parada. En este caso lo haremos en las cercanías del Barranco de Valdivia, tomando un sendereo que conduce a las minas, situadas a la derecha de la carretera, yendo hacía Jarque. Al llegar a las minas efectuaremos una nueva parada, ahora a unos $7 \mathrm{Km}$ de la parada anterior.

En este recorrido habremos ido encontrando afloramientos del triásico; sin embargo, en las cercanías del lugar de la parada, volveremos a encontrar afloramientos de los materiales paleozoicos. Así, en este lugar nos encontramos ante tramos de esquistos y cuarcitas pertenecientes al Cámbrico.

Entre estos materiales se hacen patentes unas mineralizaciones sedimentarias de hierro, relacionadas con los materiales acabados de citar. Entre estos minerales se encuentran los siguientes: GOETHITA (en forma de LIMONITA), HEMATITES y MAGNETITA. Cabe señalar que entorno al Barranco y a la loma de Valdivia existen diversas antiguas explotaciones, todas ellas de carácter subterráneo. Por otra parte, en las inmediaciones de la Caseta del Calvo hubo 
otras explotaciones similares. Sin embargo, ni un caso ni el otro nos ha quedado más patrimonio minero que los propios pozos de las minas y las escombreras. (fotografia 13).

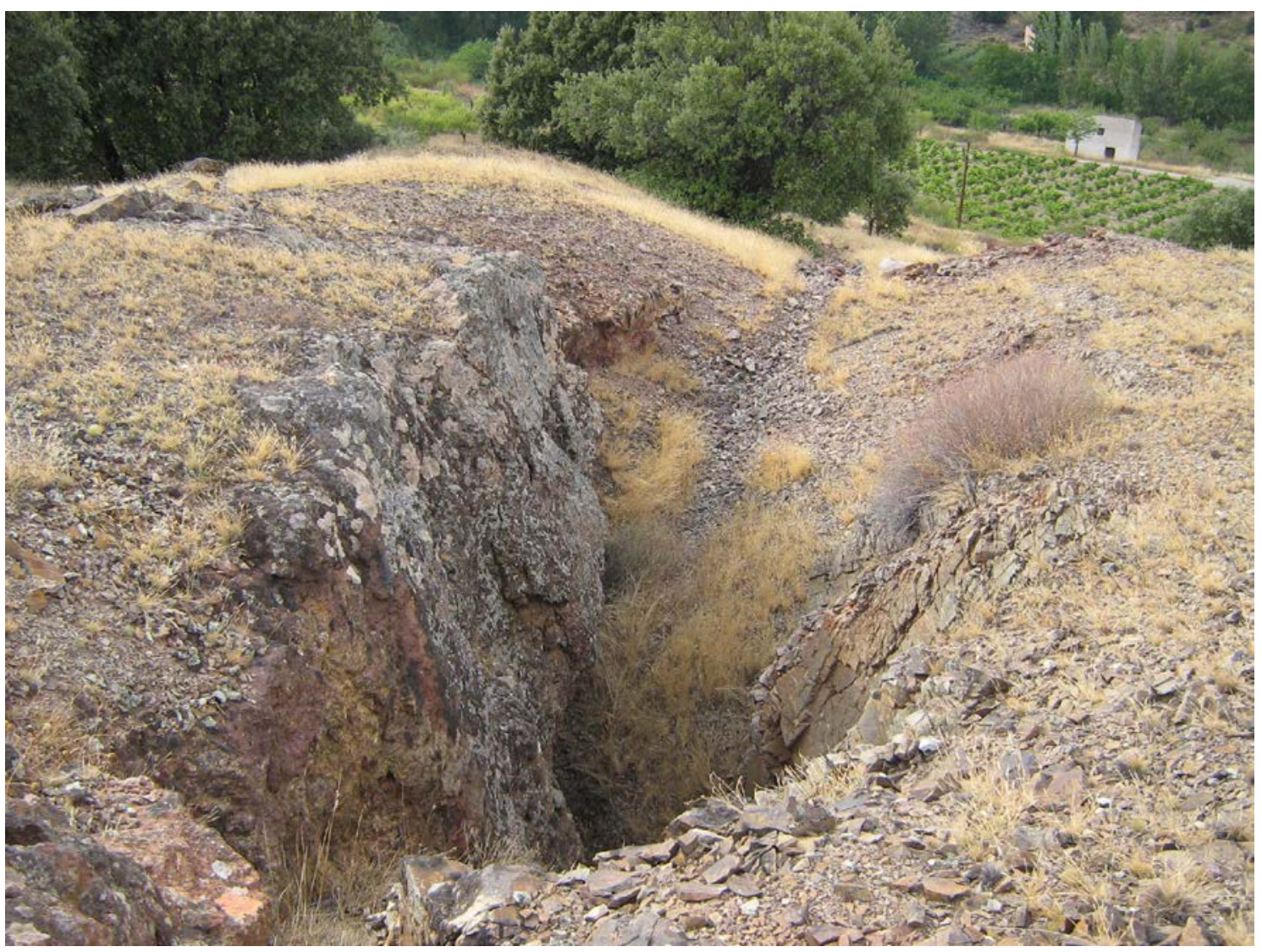

Fotografía 13. Uno de los pozos de la Loma de Valdavia 


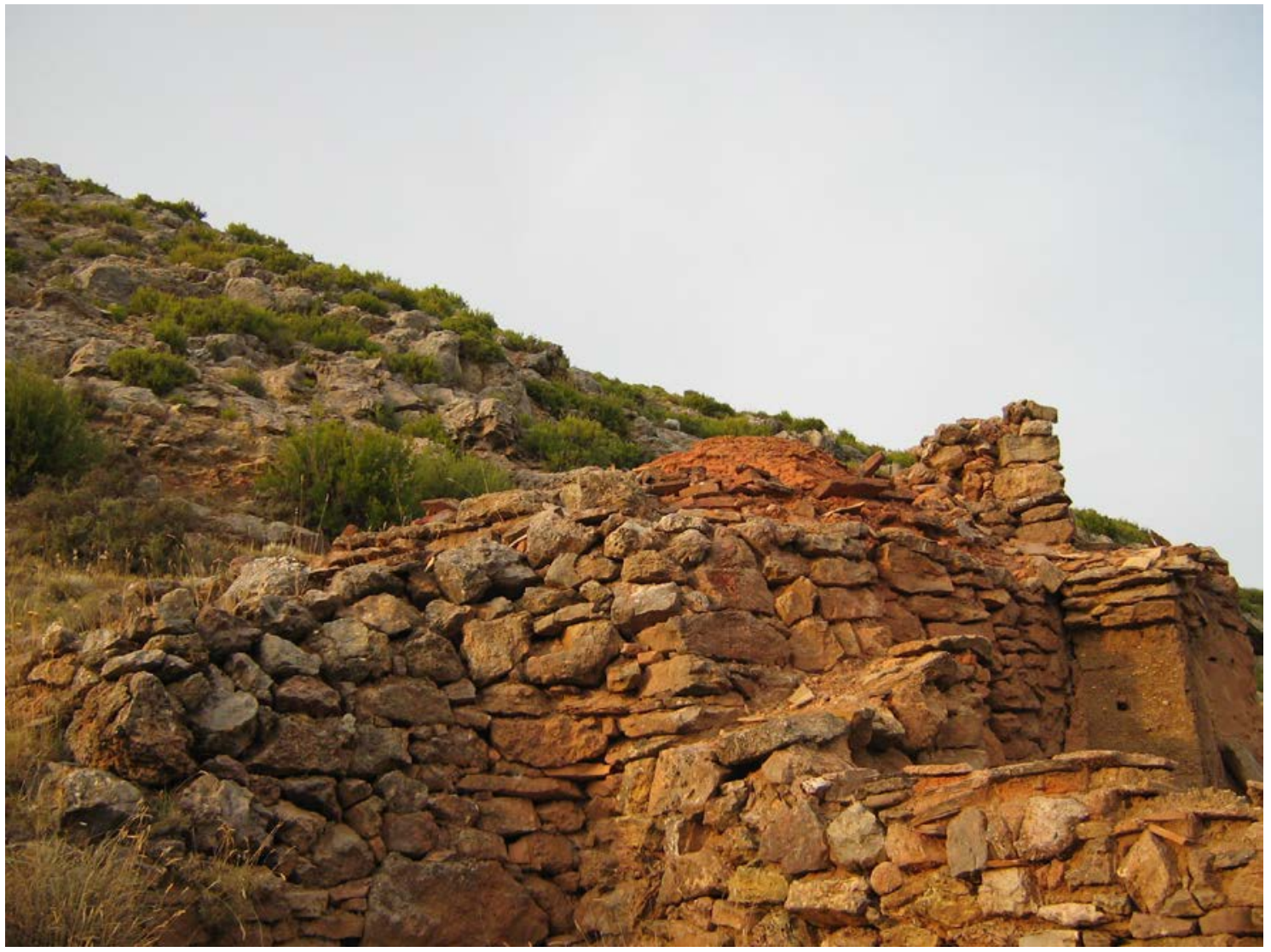

Fotografía 14. Otra muestra del horno, con su cobertura

\section{EN ESTE LUGAR FINALIZA EL RECORRIDO DEL PRESENTE ITINERARIO}

\section{BIBLIOGRAFIA}

GUIMERÀ, J. et altri (1992).- Geologia (II), Història Natural dels Països Catalans, Vol. 2, 547 pag. Enciclopèdia Catalana, S.A. Barcelona.

MATA-PERELLÓ, J.M. (1992).-.Inventario Mineralógico de la comarca del Aranda. Rodeno, 38, 20 pag. Manresa.

MATA-PERELLÓ, J.M. i SANZ BALAGUÉ, J. (1993).- Guía de identificación de Minerales, adaptada fundamentalmente a la Península Ibérica. Parcir, Edic. Selectas, 243 páginas. Manresa. 
RIBA ARDERIU, O. et altri (1976).- Geografia Física dels Països Catalans. Edit Ketres. 211 pàgines. Barcelona. 